\title{
Which Risk Dominates the Bond Yield? Empirical Tests from Market Sentiment Perspective
}

\author{
Huijian Dong ${ }^{1} \&$ Michelle Cowing ${ }^{1}$ \\ ${ }^{1}$ College of Business, Pacific University, United States \\ Correspondence: Huijian Dong, College of Business, Pacific University, United States. E-mail: \\ hdong@pacificu.edu
}

Received: December 16, 2014

Accepted: January 22, 2015

Online Published: April 20, 2015

doi:10.5539/ijbm.v10n5p10

URL: http://dx.doi.org/10.5539/ijbm.v10n5p10

\begin{abstract}
This paper adopts the Constant Maturity Treasury (CMT) issuance and the Treasury Inflation Protected Securities (TIPS) to strip the general credit risk and liquidity risk of bonds. By reclassifying the reinvestment risk as a type of interest risk, we analyze the yield spread of inflation risk and interest rate risk. As TIPS is free of inflation risk, we focus on the source of its unique major risk: interest rate risk. We employ daily data and Granger causality test and Johansen cointegration test to conclude that market sentiment, measured by the Chicago volatility (VIX) series, affects the yield related to interest rate risk significantly. Such impact is persistent in all different term of maturity over 10 years. However, when inflation risk is present, market sentiment fails to dominate the yield spread.
\end{abstract}

Keywords: bond yield, interest rate risk, CMT, TIPS, VIX, market sentiment

\section{Introduction}

The financial academia and industry generally recognize five risks for various types of bonds: interest rate risk, which refers to the price volatility of bond in terms of the change in interest rate; reinvestment risk, which is the risk of failing to reinvest proceeds at the initially higher interest rate; inflation risk, which erodes the intrinsic value of future cash flows; credit risk, which refers to the partial or full loss of future cash flows due to counterparty default; and liquidity risk, which causes the deviation of fair value and realizable value of the bond.

While downgrade risk is sometimes regarded as another source of risk (Ng \& Phelps, 2011; Acharya et al., 2013), the factors that trigger downgrade are incorporated in the five types of risks stated above. In addition, reinvestment risk can be regarded as a subset of interest risk to a large extent because of two reasons: first, the volatility of bond price leads to the change of the yield and the uncertainty of reinvestment return; second, reinvestment risk only exists after the bond is sold or matures for zero-coupon bonds and such risk and interest rate risk are homogeneous. Therefore our study recognizes four major risks of bonds: interest rate risk, inflation risk, credit risk, and liquidity risk.

Numerous literatures contribute to the relationship between these risks and the bond yield (Nashikkar et al., 2011; Maltritz \& Molchanov, 2013), as risk premium and risk factor is the keystone in modern financial theory. However, few previous studies separate the risks and examine their impacts to bond spread individually. This is mainly due to the difficulty of the separation of risks by their sources, as well as the endogeneity among risks. Our paper attempts to separate the types of risks and identifies their sources by controlling the class of bonds (Haubrich et al., 2012) and we adopt similar strategy. The conclusion of our paper not only helps understand the impacts of various risks to the yield spread but also provides clues for designing bond vehicles for heterogeneous investor risk demand and risk hedging portfolios.

We incorporate two bond classes in this study: Constant Maturity Treasury (CMT) bond and Treasury Inflation Protected Securities (TIPS). Our time series regressions are based on the daily data of 5-year, 7-year, 10-year, 20 -year, and 30-year CMT and TIPS. CMT yields are derived from Treasury Bills, Notes, and Bonds and are frequently used by lenders to determine loan rates, especially for the loans with significant prepayment risks. Therefore, CMT is an ideal proxy for both of the on-the-run and off-the-run Treasury series. TIPS is another proxy of the Treasury series that strips the inflation risk. TIPS raisesits par value with inflation, measured by the Consumer Price Index, and guarantees its interest rate being fixed. 
As both of the bond classes represent that United States government credit, the solvency concerns from the investors are ignored. For the same reason, the liquidity risk is also regarded as being trivial for these two classes. Thus the significant risk sources for CMT are: interest rate risk, reinvestment risk, and inflation risk. In contrast, the major risk sources for TIPS are only interest rate risk, reinvestment risk.

We also include the daily data of the volatility index (VIX) series in this study. The VIX indices are measures of market sentiment from the investor side. In the previous studies, the main stream of sentiment proxy is the VIX index, for example, Ben-Rephael et al. (2012). The Chicago Board Options Exchange (CBOE) calculates the CBOE Volatility Index (VIX) as the scale of stock market volatility and it is often referred to as the "investor fear gauge". CBOE first creates the weighted average value of options with a constant maturity of 30 days to expiration. The options are based on market portfolio index option prices and incorporate information from the volatility skewness by setting a wide range of exercise prices. Four market portfolio indices are included: the Standard and Poor's 100 and 500 index, the Dow Jones Industrial Index, and the NASDAQ returns. VIX is often cited as an indicator of investor panic, as volatility signifies financial turbulence. During financial stress and periods of significant security price drops, VIX increases, and vice versa. We adopt the S\&P 500-based VIX index thereafter.

Another series of sentiment studies use the BW market sentiment index (Baker \& Wurgler, 2006, 2007). The BW index is based on first principal component of six orthogonal sentiment proxies: value-weighted dividend premium, IPO volume, first day returns on IPO, closed-end fund discount, equity share in new issues, and NYSE turnover. A significant amount of literature adopts the BW index as the barometer of market, for example, Stambaugh et al. (2012), and Laborda and Olmo (2013). The BW index is not created from the bond market and hence is not cited in our current study.

Some researches adopt the Index of Consumer Sentiment produced by the University of Michigan Survey Research Center as market sentiment indicator, for instance, Akhtar et al. (2012). However, we do not include this series in the current paper, because this variable contains only one series of monthly data and it is survey based rather than market mechanism based.

In addition, a few previous studies use the assumed mood of investors of market sentiments. Al-Hajieh et al. (2011) examine whether the mood brought by the holy month of Ramadan, a time of celebration and renewal in Muslim countries affects the Islamic Middle Eastern stock markets. Palomino et al. (2009) uses the outcomes of soccer club games as investor moods to test its relation with the stock returns. We do not adopt this method, as there is no unique and consistent event that can persistently generate a time series of quantitative investor sentiment.

Finally, existing studies also propose other measures of sentiments, such as the trading volume-based BSI (Kumar \& Lee, 2006), liquidity (Baker \& Stein, 2004), psychological evidence (Barberis et al., 1998), IPO underpricing (Hrnjić \& Sankaraguruswamy, 2011), and the Tobin's Q ratio (Grundy \& Li, 2010). These measures are incorporated in the BW index as subsets and are not appropriate for bond spread study.

We perform the Granger causality tests and Johansen cointegration tests between the sentiment series and the two bonds series to detect the function of market sentiment to interest rate risk and inflation risk. Our aim is to identify the different possible functions of market sentiment to the inflation risk and interest rate. As the CMT bond yield carries both risks and TIPS is inflation risk free, the difference of the roles of market sentiment play in these bonds can be reasonably regarded as the result of inflation risk.

The paper is organized as follows: section 2 describes the source of data and the observation pool; section 3 provides the regressions equations and the reasoning of conclusion; section 4 reports the econometric results and the analyses; and section 5 concludes.

\section{Data}

We use daily data of the CMT, TIPS and VIX series in this study. The bond data are from the FRED ${ }^{\circledR}$ Database provided by the Federal Reserve Bank of St. Louis, and the Standard and Poor's 500 VIX data is from Yahoo! ${ }^{\circledR}$ Finance. The consumer price index data is from the Bureau of Labor Statistics at the U.S. Department of Labor.The size of the observation pool is described in Table 1.

Yields on Treasury issuances at constant maturity are interpolated by the U.S. Treasury from the on the run yield curve fornon-inflation-adjusted Treasury bonds. This curve presents the closing bid yield levels on liquid Treasury securities in the over-the-counter market. Likewise, yields on inflation-indexed securities at constant maturity are interpolated from the daily yield curve for Treasury inflation protected securities. Both bond series yields are read at fixed maturities, which are 5, 7, 10, 20, and 30 years. Both interpolations are linear-relation 
based.

Table 1. Variables and time series facts

\begin{tabular}{llllll}
\hline Series & Start & End & Series & Start & End \\
\hline 5YCMT & $1 / 2 / 1962$ & $10 / 29 / 2013$ & 20YCMT & $10 / 1 / 1993$ & $10 / 29 / 2013$ \\
5YTIPS & $1 / 2 / 2003$ & $10 / 29 / 2013$ & 20YTIPS & $7 / 27 / 2004$ & $10 / 29 / 2013$ \\
7YCMT & $7 / 1 / 1969$ & $10 / 29 / 2013$ & 30YCMT & $2 / 15 / 1977$ & $10 / 29 / 2013$ \\
7YTIPS & $1 / 2 / 2003$ & $10 / 29 / 2013$ & 30YTIPS & $2 / 22 / 2010$ & $10 / 29 / 2013$ \\
10YCMT & $1 / 2 / 1962$ & $10 / 29 / 2013$ & VIX (Adjusted Close) & $1 / 2 / 1990$ & $10 / 29 / 2013$ \\
10YTIPS & $1 / 2 / 2003$ & $10 / 29 / 2013$ & Consumer Price Index & January 1913 & September 2013 \\
\hline
\end{tabular}

All the time series are non-seasonal adjusted. As the highest frequency of Consumer Price Index (CPI) available is monthly-based, we linearly interpolate the missing daily values to facilitate the plot in Figure 1. While CPI is not involved in the regressions, we list the index in the following figures to present the relationships in a straightforward way. This figure suggests certain comovement patterns of CMT with inflation. However, we find no such comovements with the TIPS series.
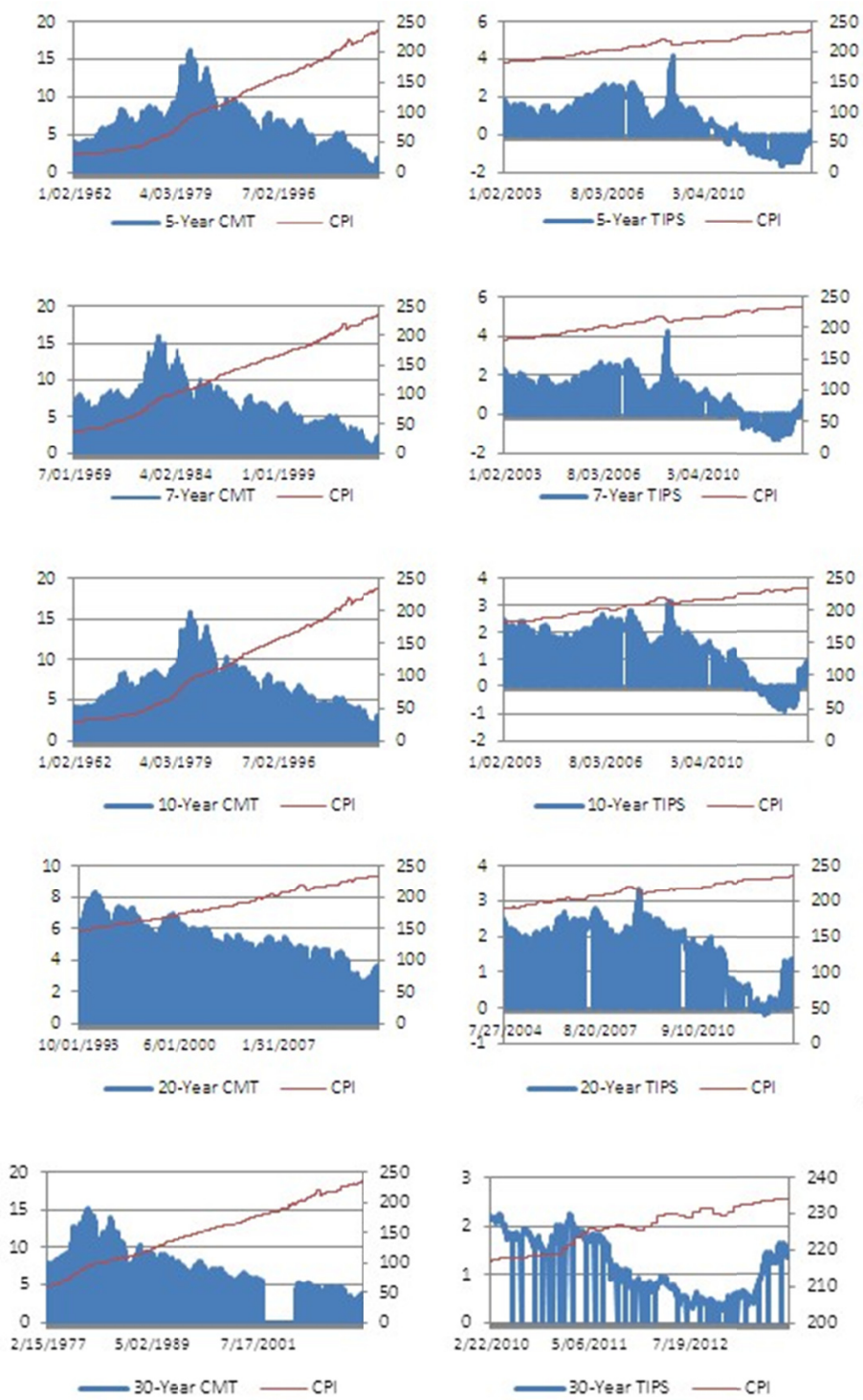

Figure 1. Constant maturity bonds, inflation protection bonds, and inflation from 1962 to 2013 


\section{Methodology}

We first follow the standard Augmented Dickey-Fuller (ADF) test procedure to examine the unit root issue. Then we proceed to perform the Granger causality tests and Johansen cointegration tests between the sentiment series and the two bonds series to detect the function of market sentiment to interest rate risk, reinvestment risk, and inflation risk. In other words, the tests examine different possible functions of market sentiment to the inflation risk and interest rate. The results can fall into the following four categories:

First, if market sentiment, represented by VIX, plays a vital role in determining the yield spread for TIPS rather than CMT, aggregate bond yield is dominated by inflation risk instead of investor optimism or pessimism. Second, if VIX significantly affects the yield spread for CMT but not TIPS, bond yield is more likely to be mispriced, as the driving factors of TIPS should be nested by those of CMT. Third, if VIX determines both of the spreads for CMT and TIPS, inflation has no role in bond market, i.e., inflation risk should not generate the corresponding risk premium. In this scenario, the pricing of Treasury series is the process of implementing investor sentiments. Fourth, if VIX does not result in any change in terms of the spreads of CMT and TIPS, the market is perfectly rational and investor sentiment does not lead to the change in demand of bonds, risk, or liquidity.

We also perform the cointegration tests and Granger causality tests among the series of CMT and TIPS bonds with heterogeneous maturities to examine the yield spread contagion and the indirect impacts of risks. The reason for this further step is to detect the endogenous factors embedded in bond yields to identify the exogenous role of inflation risk as well as market sentiment. In other words, we use this step as a robustness check of the effect of inflation risk in terms of the CMT bond.

The pre-requisite of the tests is the unit root test, which measures the degree of integration of the time series. The regression function is:

$$
\Delta y_{t}=\alpha+\beta t+\gamma y_{t-1}+\delta_{1} \Delta y_{t-1}+\cdots+\delta_{p-1} \Delta y_{t-p+1}+\varepsilon_{t}
$$

The null hypothesis is $\gamma=0$, i.e., the series has a unit root. The alternative hypothesis is $\gamma<0$, or the series is stationary. We report the results in Table 1. Following the random walk test is the Granger causality test, which is adopted to measure the mutual impact between market sentiment and bond yield. For a bivariate linear autoregressive model with pairwise variables $X_{1}$ and $X_{2}$, the test regression is:

$$
\begin{aligned}
& X_{1}(t)=\sum_{j=1}^{P} A_{11, j} X_{1}(t-j)+\sum_{j=1}^{P} A_{12, j} X_{2}(t-j)+E_{1}(t) \\
& X_{2}(t)=\sum_{j=1}^{P} A_{21, j} X_{1}(t-j)+\sum_{j=1}^{P} A_{22, j} X_{2}(t-j)+E_{2}(t)
\end{aligned}
$$

$\mathrm{P}$ in the regression equations is the maximum number of lags included, and the matrix $\mathrm{A}$ is the plain vanilla VAR coefficients. $E$. $(t)$ is the regression residual. If the variance of $E$. $(t)$ is improved by adding $X_{1}$ or $X_{2}$, it implies that $X_{1}$ or $X_{2}$ Granger causes $X_{2}$ or $X_{1}$. The way to detect such improvement is by testing whether, for example, the coefficients carried by $A_{12}$ are jointly different from zero. If the null hypothesis of $A_{12}=0$ is rejected significantly by the $\mathrm{F}$ test, $X_{2}$ Granger causes $X_{1}$. We use the Bayesian Information Criterion (BIC) to determine the number of lags. The results are presented in Table 3 and 5. We also perform the cointegration tests between the bond series and sentiment series to identify the comovement pattern of the bond market and investor expectation. The procedure is based on the Vector Error Correlation Model (VECM) and it follows the results of the unit root tests. For the pairwise cointegration test, the regression is: for a VAR of order $\mathrm{p}$ :

$$
y_{t}=A_{1} y_{t-1}+\cdots+A_{p} y_{t-p}+B x_{t}+\epsilon_{t}
$$

Where $y_{t}$ is a k-vector of non-stationary I(1) variables, $x_{t}$ is a d-vector of deterministic variable, and the error term is a vector of innovations. Using the first-order difference form, the VAR can be rewritten as:

$$
\Delta y_{t}=\Pi \mathrm{y}_{\mathrm{t}-1}+\sum_{\mathrm{i}=1}^{\mathrm{p}-1} \Gamma_{\mathrm{i}} \Delta \mathrm{y}_{\mathrm{t}-\mathrm{i}}+\mathrm{Bx}_{\mathrm{t}}+\epsilon_{t}, \text { where } \Pi=\sum_{i=1}^{p} A_{i}-I \text {, and } \Gamma_{i}=-\sum_{j=i+1}^{p} A_{j}
$$

If the coefficient matrix $\Pi$ has reduced rank $\mathrm{r}<\mathrm{k}$, then there exists $k \times r$ matrices $\alpha$ and $\beta$ each with rank $\mathrm{r}$ such that $\Pi=\alpha \beta^{\prime}$ and $\beta^{\prime} y_{t}$ is $\mathrm{I}(0)$. $\mathrm{r}$ is the number of cointegrating relations, or the rank. The results are exhibited in Table 4 and 6.

\section{Results and Discussion}

The results of the two groups of tests are highly consistent. Table 3 suggests that market sentiment significantly affects the inflation-adjusted yield of Treasury (TIPS) issues but not the constant maturity treasury series (CMT). When a bond incorporates the inflation risk, the impact of market sentiment has a limit role in terms of the yield spread of bonds. Therefore it is plausible to conclude that interest risk dominates the bond yields when inflation risk is absent; however, inflation risk dominates the yields when it is present. Inflation risk overrides interest risk, 
and the latter is significantly affected by investor sentiment. The counter-direction causality does not hold: neither inflation risk nor interest risk has strong impact on investor sentiment.

Specifically, other than the anomaly of the causality from VIX to 10-year CMT bond, the VIX series fails to Granger cause the CMT series significantly at 5\% level. Such anomaly is reasonable as the 10 -year CMT is particularly cited for the setting of mortgage rate and primary rate. At $1 \%$ level, VIX has no impact on the yield of CMT. In contrast, the VIX series strongly affects the TIPS bonds at almost all levels of maturity, as reported in Table 3. Such comparison leads to the conclusion that market sentiment only dominates the interest risk when an asset is inflation risk free.

The unit root test procedure is the standard Augmented Dickey-Fuller test and the regression is described by Equation (1). We use MacKinnon (1996) one-sided p-values as the indicator of significance level. The null hypothesis is the time series is not stationary, i.e., the variable has a unit root.

Table 2. The results of unit root tests of CMT, TIPS, and market sentiment series

\begin{tabular}{llllll}
\hline Variable & t-Statistics & P Value & Variable & t-Statistics & P Value \\
\hline 5YCMT & -0.653867 & 0.8561 & 20YCMT & -1.2125 & 0.6714 \\
5YTIPS & -1.611305 & 0.4766 & 20YTIPS & -1.48077 & 0.5434 \\
7YCMT & -0.332914 & 0.9177 & 30YCMT & -0.33535 & 0.9173 \\
7YTIPS & -1.589715 & 0.4877 & 30YTIPS & -1.65733 & 0.4527 \\
10YCMT & -0.781504 & 0.8237 & VIX & -3.79704 & 0.0030 \\
10YTIPS & -1.537665 & 0.5144 & & & \\
\hline
\end{tabular}

We use a pairwise Granger causality method. The procedure is described in Equation (2) and (3). The columns of variable description indicate the direction of causality. The null hypothesis is the absence of causality. For example, as the $\mathrm{p}$ value of VIX to 5YTIPS rejects the null hypothesis, VIX Granger causes 5YTIPS.

Table 3. Granger causality between bonds and market sentiment

\begin{tabular}{llllll}
\hline Variable & F-Statistics & P Value & Variable & F-Statistics & P Value \\
\hline VIX to 5YCMT & 1.74096 & 0.1380 & 5YCMT to VIX & 0.78207 & 0.5366 \\
VIX to 5YTIPS & 12.5603 & 0.0000 & 5YTIPS to VIX & 1.48201 & 0.2050 \\
VIX to 7YCMT & 2.05712 & 0.0837 & 7YCMT to VIX & 0.57092 & 0.6838 \\
VIX to 7YTIPS & 13.9747 & 0.0000 & 7YTIPS to VIX & 1.33649 & 0.2540 \\
VIX to 10YCMT & 2.95977 & 0.0187 & 10YCMT to VIX & 0.64643 & 0.6294 \\
VIX to 10YTIPS & 11.3345 & 0.0000 & 10YTIPS to VIX & 1.52184 & 0.1931 \\
VIX to 20YCMT & 1.53499 & 0.1892 & 20YCMT to VIX & 0.36016 & 0.8371 \\
VIX to 20YTIPS & 6.24568 & 0.0001 & 20YTIPS to VIX & 0.97185 & 0.4217 \\
VIX to 30YCMT & 2.46608 & 0.0429 & 30YCMT to VIX & 1.12719 & 0.3417 \\
VIX to 30YTIPS & 2.20233 & 0.0671 & 30YTIPS to VIX & 1.40852 & 0.2293 \\
\hline
\end{tabular}

The cointegration test follows the Johansen procedure as described in Equation (5). For the three options of data trend: no trend, linear trend, and quadratic trend, this paper assumes that the data trend is absent. However, we do not exclude the intercept of the time series regression. This table hence reports results with two test settings: no intercept no trend, and intercept no trend. We adopt two criteria for the number of cointegration relationships: trace method, and maximum eigenvalue method. The results reported in this table are the number of significant cointegration relationships between the pairwise variables. The critical values are based on MacKinnon-Haug-Michelis (1999), all at 0.05 levels. 
Table 4. Cointegration between bonds and market sentiment

\begin{tabular}{|c|c|c|c|c|c|}
\hline & No intercept no trend & & rcept no trend & No intercept no trend & Intercept no trend \\
\hline Series: 5YCMT VIX & & & Series: 10YTIPS VIX & & \\
\hline Trace & 1 & 1 & Trace & 0 & 0 \\
\hline Maximum Eigenvalue & 1 & 1 & Maximum Eigenvalue & 0 & 0 \\
\hline Series: 5YTIPS VIX & & & Series: 20YCMT VIX & & \\
\hline Trace & 0 & 1 & Trace & 1 & 1 \\
\hline Maximum Eigenvalue & 0 & 1 & Maximum Eigenvalue & 1 & 1 \\
\hline Series: 7YCMT VIX & & & Series: 20YTIPS VIX & & \\
\hline Trace & 1 & 1 & Trace & 0 & 0 \\
\hline Maximum Eigenvalue & 1 & 1 & Maximum Eigenvalue & 0 & 0 \\
\hline Series: 7YTIPS VIX & & & Series: 30YCMT VIX & & \\
\hline Trace & 0 & 0 & Trace & 1 & 1 \\
\hline Maximum Eigenvalue & 0 & 1 & Maximum Eigenvalue & 1 & 1 \\
\hline Series: 10YCMT VIX & & & Series: 30YTIPS VIX & & \\
\hline Trace & 1 & 1 & Trace & 0 & 0 \\
\hline Maximum Eigenvalue & 1 & 1 & Maximum Eigenvalue & 0 & 0 \\
\hline
\end{tabular}

The regression method is described in Table 3. A significant rejection $(\mathrm{p}<0.05)$ of the null hypothesis implies the existence of causality.

Table 5. Granger causality of $\mathrm{cmt}$ and tips yields in the u.s. market from 1962 to 2013

\begin{tabular}{|c|c|c|c|c|c|c|c|c|}
\hline \multicolumn{9}{|c|}{ Panel A: Granger Causality among Constant Maturity Treasury Bonds with Heterogeneous Terms } \\
\hline Variable & F-Statistics & P Value & Variable & F-Statistics & P Value & Variable & F-Statistics & P Value \\
\hline 5YCMT to $7 \mathrm{YCMT}$ & 8.0201 & 0.0000 & 7YCMT to $30 \mathrm{YCMT}$ & 1.2843 & 0.2736 & $20 \mathrm{YCMT}$ to $10 \mathrm{YCMT}$ & 2.6375 & 0.0323 \\
\hline $5 \mathrm{YCMT}$ to $10 \mathrm{YCMT}$ & 6.0628 & 0.0001 & 10YCMT to $5 \mathrm{YCMT}$ & 1.7283 & 0.1406 & $20 \mathrm{YCMT}$ to $30 \mathrm{YCMT}$ & 0.9740 & 0.4204 \\
\hline $5 \mathrm{YCMT}$ to $20 \mathrm{YCMT}$ & 1.4926 & 0.2016 & 10YCMT to $7 \mathrm{YCMT}$ & 6.6707 & 0.0000 & $30 \mathrm{YCMT}$ to $5 \mathrm{YCMT}$ & 0.7093 & 0.5855 \\
\hline $5 \mathrm{YCMT}$ to $30 \mathrm{YCMT}$ & 0.5018 & 0.7345 & $10 \mathrm{YCMT}$ to $20 \mathrm{YCMT}$ & 3.1026 & 0.0146 & $30 \mathrm{YCMT}$ to $7 \mathrm{YCMT}$ & 1.8290 & 0.1202 \\
\hline 7YCMT to $5 \mathrm{YCMT}$ & 0.7810 & 0.5373 & $10 \mathrm{YCMT}$ to $30 \mathrm{YCMT}$ & 2.9084 & 0.0204 & $30 \mathrm{YCMT}$ to $10 \mathrm{YCMT}$ & 0.5821 & 0.6756 \\
\hline $7 \mathrm{YCMT}$ to $10 \mathrm{YCMT}$ & 5.1820 & 0.0004 & $20 \mathrm{YCMT}$ to $5 \mathrm{YCMT}$ & 1.7904 & 0.1278 & $30 \mathrm{YCMT}$ to $20 \mathrm{YCMT}$ & 0.6567 & 0.6221 \\
\hline $7 \mathrm{YCMT}$ to $20 \mathrm{YCMT}$ & 1.7415 & 0.1379 & 20YCMT to $7 \mathrm{YCMT}$ & 2.1423 & 0.0730 & & & \\
\hline
\end{tabular}

Panel B: Granger Causality among Treasury Inflation Protected Securities with Heterogeneous Terms

\begin{tabular}{llllllllll} 
Variable & \multicolumn{2}{l}{ F-Statistics P Value Variable } & \multicolumn{2}{l}{ F-Statistics } & P Value Variable & F-Statistics P Value \\
\hline 5YTIPS to 7YTIPS & 5.4143 & 0.0002 & 7YTIPS to 30YTIPS & 1.8537 & 0.1167 & 20YTIPS to 10YTIPS & 5.9873 & 0.0001 \\
5YTIPS to 10YTIPS & 1.7166 & 0.1435 & 10YTIPS to 5YTIPS & 3.6514 & 0.0057 & 20YTIPS to 30YTIPS & 0.4004 & 0.8085 \\
5YTIPS to 20YTIPS & 7.2265 & 0.0000 & 10YTIPS to 7YTIPS & 3.7498 & 0.0048 & 30 YTIPS to 5YTIPS & 3.8785 & 0.0040 \\
5YTIPS to 30YTIPS & 1.2068 & 0.3064 & 10YTIPS to 20YTIPS & 6.7540 & 0.0000 & 30 YTIPS to 7YTIPS & 1.9797 & 0.0957 \\
7YTIPS to 5YTIPS & 2.6701 & 0.0307 & 10YTIPS to 30YTIPS & 1.6644 & 0.1563 & 30YTIPS to 10YTIPS & 2.6379 & 0.0329 \\
7YTIPS to 10YTIPS & 1.3501 & 0.2490 & 20YTIPS to 5YTIPS & 4.9950 & 0.0005 & 30 YTIPS to 20YTIPS & 2.1902 & 0.0684
\end{tabular}

Panel C: Granger Causality from Constant Maturity Treasury to Treasury Inflation Protected Securities

\begin{tabular}{lllllllll} 
Variable & \multicolumn{2}{c}{ F-Statistics P Value Variable } & F-Statistics & P Value Variable & F-Statistics P Value \\
\hline 5YCMT to 5YTIPS & 11.3460 & 0.0000 & 7YCMT to 30YTIPS & 0.3719 & 0.8288 & 20YCMT to 20YTIPS & 9.6783 & 0.0000 \\
5YCMT to 7YTIPS & 4.5911 & 0.0011 & 10YCMT to 5YTIPS & 16.2662 & 0.0000 & 20YCMT to 30YTIPS & 1.1054 & 0.3528 \\
5YCMT to 10YTIPS & 6.4878 & 0.0000 & 10YCMT to 7YTIPS & 7.7026 & 0.0000 & 30YCMT to 5YTIPS & 20.5155 & 0.0000 \\
5YCMT to 20YTIPS & 3.6160 & 0.0061 & 10YCMT to 10YTIPS & 9.2319 & 0.0000 & 30YCMT to 7YTIPS & 12.1693 & 0.0000 \\
5YCMT to 30YTIPS & 0.2848 & 0.8879 & 10YCMT to 20YTIPS 5.2095 & 0.0004 & 30YCMT to 10YTIPS & 13.8666 & 0.0000 \\
7YCMT to 5YTIPS & 14.2023 & 0.0000 & 10YCMT to 30YTIPS & 0.5346 & 0.7104 & 30YCMT to 20YTIPS & 9.7780 & 0.0000
\end{tabular}




\begin{tabular}{|c|c|c|c|c|c|c|c|c|}
\hline 7YCMT to 7YTIPS & 5.9923 & 0.0001 & 20YCMT to 5YTIPS & 19.0561 & 0.0000 & 30YCMT to $30 \mathrm{YTIPS}$ & 0.9639 & 0.4265 \\
\hline 7YCMT to $10 Y$ TIPS & 7.2824 & 0.0000 & 20YCMT to 7YTIPS & 10.8656 & 0.0000 & & & \\
\hline 7YCMT to 20YTIPS & 3.5785 & 0.0065 & 20YCMT to $10 \mathrm{YTIPS}$ & 12.4736 & 0.0000 & & & \\
\hline \multicolumn{9}{|c|}{ Panel D: Granger Causality from Treasury Inflation Protected Securities to Constant Maturity Treasury } \\
\hline Variable & F-Statistics & P Value & Variable & F-Statistics & P Value & Variable & F-Statistics & P Value \\
\hline 5YTIPS to 5YCMT & 2.7010 & 0.0291 & 7YTIPS to 30YCMT & 1.0209 & 0.3952 & 20YTIPS to 20YCMT & 0.2988 & 0.8788 \\
\hline 5YTIPS to 7YCMT & 2.0108 & 0.0904 & $10 \mathrm{YTIPS}$ to $5 \mathrm{YCMT}$ & 1.5687 & 0.1799 & 20YTIPS to $30 \mathrm{YCMT}$ & 0.4991 & 0.7365 \\
\hline 5YTIPS to $10 \mathrm{YCMT}$ & 1.6465 & 0.1599 & 10YTIPS to $7 \mathrm{YCMT}$ & 1.6525 & 0.1584 & $30 \mathrm{YTIPS}$ to $5 \mathrm{YCMT}$ & 1.8443 & 0.1184 \\
\hline 5 YTIPS to $20 \mathrm{YCMT}$ & 1.5580 & 0.1829 & 10YTIPS to $10 \mathrm{YCMT}$ & 1.2152 & 0.3022 & $30 \mathrm{YTIPS}$ to $7 \mathrm{YCMT}$ & 2.0679 & 0.0832 \\
\hline 5YTIPS to $30 \mathrm{YCMT}$ & 0.8197 & 0.5125 & 10YTIPS to $20 \mathrm{YCMT}$ & 0.5074 & 0.7303 & $30 \mathrm{YTIPS}$ to $10 \mathrm{YCMT}$ & 1.4747 & 0.2080 \\
\hline 7YTIPS to $5 \mathrm{YCMT}$ & 2.4920 & 0.0413 & $10 \mathrm{YTIPS}$ to $30 \mathrm{YCMT}$ & 0.3419 & 0.8498 & 30 YTIPS to $20 \mathrm{YCMT}$ & 0.8149 & 0.5158 \\
\hline 7YTIPS to 7YCMT & 2.4727 & 0.0426 & $20 \mathrm{YTIPS}$ to $5 \mathrm{YCMT}$ & 0.9645 & 0.4258 & $30 \mathrm{YTIPS}$ to $30 \mathrm{YCMT}$ & 1.1587 & 0.3278 \\
\hline 7YTIPS to $10 \mathrm{YCMT}$ & 2.2812 & 0.0584 & 20YTIPS to 7YCMT & 0.9631 & 0.4266 & & & \\
\hline 7 YTIPS to 20 YCMT & 1.4477 & 0.2157 & 20YTIPS to $10 \mathrm{YCMT}$ & 0.4345 & 0.7838 & & & \\
\hline
\end{tabular}

The cointegration test follows the Johansen procedure as described in Equation (5). For the same reason stated in Table 4, this table reports results with the test settings of no intercept no trend and intercept no trend, and with the criteria settings of trace method and maximum eigenvalue method. The results reported in this table are the number of significant cointegration relationships between the pairwise variables. The critical values are based on MacKinnon-Haug-Michelis (1999), all at 0.05 levels.

Table 6. Cointegrationof CMT and TIPS yields in the U.S. market from 1962 to 2013

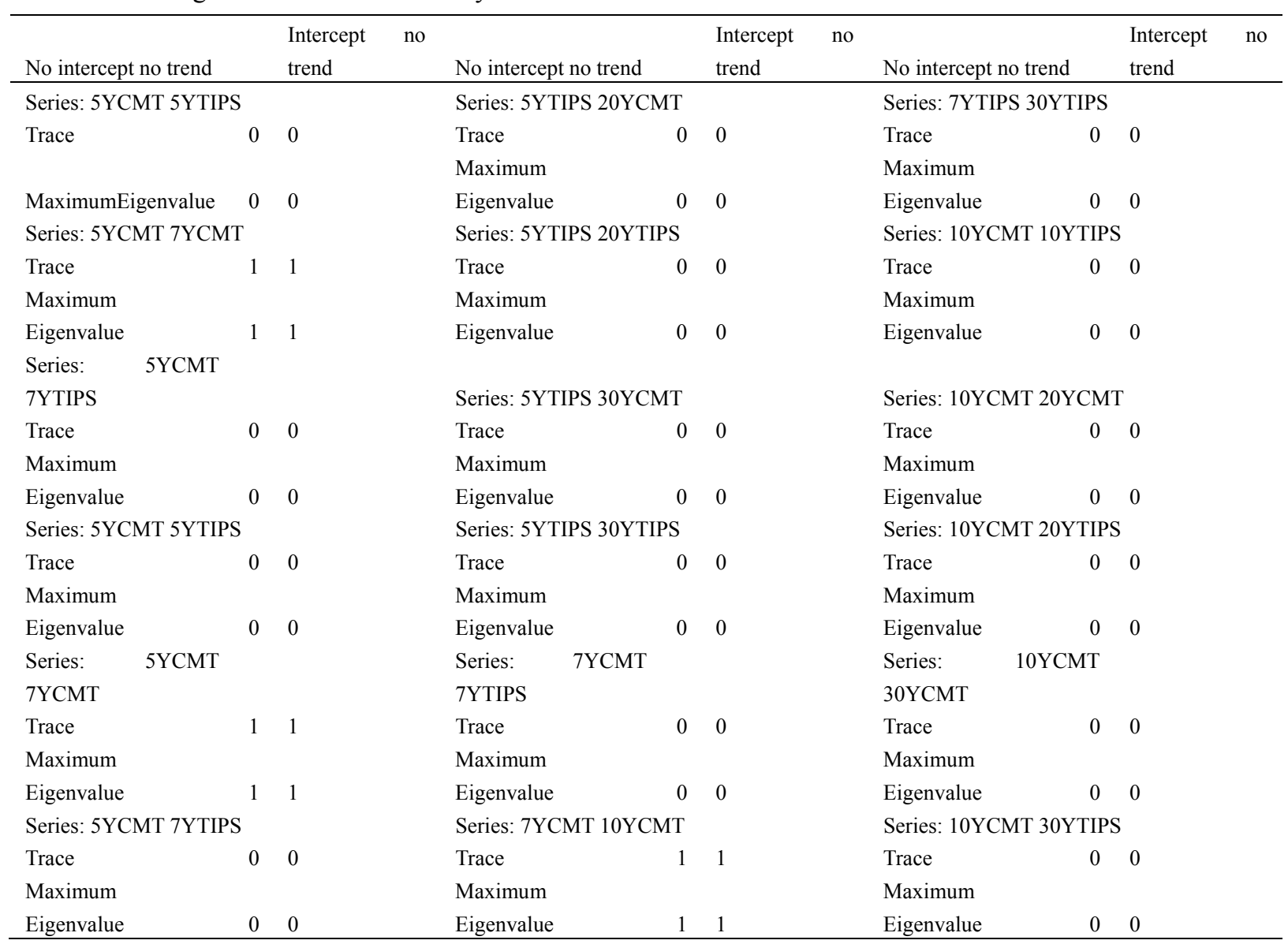




\begin{tabular}{|c|c|c|c|c|c|c|c|c|}
\hline \multicolumn{3}{|c|}{ Series: 5YCMT 10YCMT } & \multicolumn{3}{|c|}{ Series: 7YCMT 10YTIPS } & \multicolumn{3}{|c|}{ Series: 10YTIPS 20YCMT } \\
\hline Trace & 1 & 0 & Trace & 0 & 0 & Trace & 0 & 0 \\
\hline \multicolumn{3}{|l|}{ Maximum } & \multicolumn{3}{|l|}{ Maximum } & \multicolumn{3}{|l|}{ Maximum } \\
\hline Eigenvalue & 1 & 1 & Eigenvalue & 0 & 0 & Eigenvalue & 0 & 0 \\
\hline \multicolumn{3}{|c|}{ Series: 5YCMT 10YTIPS } & \multicolumn{3}{|c|}{ Series: 7YCMT 20YCMT } & \multicolumn{3}{|c|}{ Series: 10YTIPS 20YTIPS } \\
\hline Trace & 0 & 0 & Trace & 0 & 0 & Trace & 0 & 0 \\
\hline \multicolumn{3}{|l|}{ Maximum } & \multicolumn{3}{|l|}{ Maximum } & \multicolumn{3}{|l|}{ Maximum } \\
\hline Eigenvalue & 0 & 0 & Eigenvalue & 0 & 0 & Eigenvalue & 0 & 0 \\
\hline \multicolumn{3}{|c|}{ Series: 5YCMT 20YCMT } & \multicolumn{3}{|c|}{ Series: 7YCMT 20YTIPS } & \multicolumn{3}{|c|}{ Series: 10YTIPS 30YCMT } \\
\hline Trace & 0 & 0 & Trace & 0 & 0 & Trace & 0 & 0 \\
\hline \multicolumn{3}{|l|}{ Maximum } & \multicolumn{3}{|l|}{ Maximum } & \multicolumn{3}{|l|}{ Maximum } \\
\hline Eigenvalue & 0 & 0 & Eigenvalue & 0 & 0 & Eigenvalue & 0 & 0 \\
\hline \multicolumn{3}{|c|}{ Series: 5YCMT 20YTIPS } & \multicolumn{3}{|c|}{ Series: 7YCMT 30YCMT } & \multicolumn{3}{|c|}{ Series: 10YTIPS 30YTIPS } \\
\hline Trace & 0 & 0 & Trace & 0 & 0 & Trace & 0 & 0 \\
\hline \multicolumn{3}{|l|}{ Maximum } & \multicolumn{3}{|l|}{ Maximum } & \multicolumn{3}{|l|}{ Maximum } \\
\hline Eigenvalue & 0 & 0 & Eigenvalue & 0 & 0 & Eigenvalue & 0 & 0 \\
\hline Series: $5 \mathrm{YCl}$ & & & Series: 7YC & & & Series: $20 \mathrm{YC}$ & TIP & \\
\hline Trace & 0 & 0 & Trace & 0 & 0 & Trace & 0 & 0 \\
\hline Maximum & & & Maximum & & & Maximum & & \\
\hline Eigenvalue & 0 & 0 & Eigenvalue & 0 & 0 & Eigenvalue & 0 & 0 \\
\hline Series: $5 \mathrm{YCl}$ & & & Series: $7 \mathrm{YT}$ & & & Series: $20 \mathrm{YC}$ & $\mathrm{CM}$ & \\
\hline Trace & 0 & 0 & Trace & 0 & 0 & Trace & 0 & 0 \\
\hline Maximum & & & Maximum & & & Maximum & & \\
\hline Eigenvalue & 0 & 0 & Eigenvalue & 0 & 0 & Eigenvalue & 0 & 0 \\
\hline Series: $5 \mathrm{YTI}$ & & & Series: 7YT & & & Series: $20 \mathrm{YC}$ & TIP & \\
\hline Trace & 0 & 0 & Trace & 0 & 0 & Trace & 0 & 0 \\
\hline Maximum & & & Maximum & & & Maximum & & \\
\hline Eigenvalue & 0 & 0 & Eigenvalue & 0 & 0 & Eigenvalue & 0 & 0 \\
\hline Series:5YTII & & & & & & & & \\
\hline S & & & Series: $7 Y T$ & & & Series: $20 \mathrm{YT}$ & $\mathrm{CM}$ & \\
\hline Trace & 0 & 0 & Trace & 0 & 0 & Trace & 0 & 0 \\
\hline Maximum & & & Maximum & & & Maximum & & \\
\hline Eigenvalue & 0 & 0 & Eigenvalue & 0 & 0 & Eigenvalue & 0 & 0 \\
\hline Series: $5 \mathrm{YTI}$ & & & Series: $7 Y T$ & & & Series: $20 \mathrm{Y}$ & TIP & \\
\hline Trace & 0 & 0 & Trace & 0 & 0 & Trace & 0 & 0 \\
\hline Maximum & & & Maximum & & & Maximum & & \\
\hline Eigenvalue & 0 & 0 & Eigenvalue & 0 & 0 & Eigenvalue & 0 & 0 \\
\hline Series: $5 \mathrm{YTI}$ & & & Series: 7YT & & & Series: $30 \mathrm{YT}$ & $\mathrm{CM}$ & \\
\hline Trace & 0 & 0 & Trace & 0 & 0 & Trace & 0 & 0 \\
\hline Maximum & & & Maximum & & & Maximum & & \\
\hline Eigenvalue & 0 & 0 & Eigenvalue & 0 & 0 & Eigenvalue & 0 & 0 \\
\hline
\end{tabular}

\section{Concluding Remarks}

In this paper, we first categorize the five risk factors of bond premium: interest rate, reinvestment, inflation, credit, liquidity risk. By adopting the constant maturity bond (CMT) and treasury inflation protection security (TIPS) in the time series study, we restrict the reinvestment, credit, and liquidity risk premium. We attempt to examine the source and impact of the interest rate risk and inflation risk to CMT yield spread, and the interest risk to TIPS yield spread.Our time series regressions are based on the daily data of 5-year, 7-year, 10-year, 20-year, and 30-year CMT and TIPS from 1962 to 2013. We also include the daily data of the volatility index (VIX) series as measures of market sentiment from the investor side.

We find that when a bond incorporates the inflation risk, the impact of market sentiment has a limit role on the yield spread of the bond. Interest rate risk dominates the bond yields when inflation risk is absent; however, inflation risk dominates the yields when it is present. Inflation risk overrides interest rate risk, and the latter is significantly affected by investor sentiment. In contrast, bond risks do not affect investor sentiment. The cointegration regressions also suggest the limited role of market sentiment in the long run to the interest rate risk, 
and the existence of other unknown risk loadings for long term TIPS, when inflation risk does not present.

In addition, this paper attempts to detect the endogenous risk loadings of CMT and TIPS. The endogenous risk factors of CMT are more significant in the short and mid-term bonds; and that of TIPS are significant in all terms of maturities. This supports the conclusion of the existence of idiosyncratic risk component of TIPS. Such unique risk premium is persistent and contagious in the same bond class, yet is absent for CMT. The yield of CMT significantly leads to the change of the yield of TIPS, inflation risk dominates interest rate risk to a large extent. Market sentiment leads to the fluctuation of TIPS yield, yet the contagion ceases. There is a firewall between CMT and TIPS that prevents the spread CMT from being priced by market fear.

In the further study, we plan to explore the impact of market sentiment and inflation risk on the other risk loadings, mainly credit risk and liquidity risk. The primary preparation for the next step is to identify bond instruments that carry one type of risk but is free for another. Such single asset class does not exist in the market and we plan to assemble an arbitrage-free portfolio that mimics the risk and yield pattern. This has the similar motivation and function with our choice of CMT and TIPS in this current paper

\section{References}

Acharya, V. V., Yakov, A., \& Sreedhar, T. B. (2013). Liquidity risk of corporate bond returns: Conditional approach. Journal of Financial Economics, 110(2), 358. http://dx.doi.org/10.1016/j.jfineco.2013.08.002

Akhtar, S., Faff, R., Oliver, B., \& Subrahmanyam, A. (2012). Stock salience and the asymmetric market effect of consumer sentiment news. Journal of Banking \& Finance, 36, 3289-3301. http://dx.doi.org/10.1016/j.jbankfin.2012.07.019

Al-Hajieh, H., Redhead, K., \& Rodgers, T. (2011). Investor sentiment and calendar anomaly effects: A case study of the impact of Ramadan on Islamic Middle Eastern markets. Research in International Business and Finance, 25, 345-356. http://dx.doi.org/10.1016/j.ribaf.2011.03.004

Amrut N. M., Subrahmanyam, G., \& Sriketan, M. (2011). Liquidity and Arbitrage in the Market for Credit Risk. Journal of Financial and Quantitative Analysis, 46(3), 627-656. http://dx.doi.org/10.1017/S002210901100007X

Baker, M., \& Stein, J. C. (2004). Market liquidity as a sentiment indicator. Journal of Financial Markets, 7 , 271-299. http://dx.doi.org/10.1016/j.finmar.2003.11.005

Baker, M., \& Wurgler, J. (2006). Investor sentiment and the cross-section of stock returns. The Journal of Finance, 61, 1125-1165. http://dx.doi.org/10.1111/j.1540-6261.2006.00885.x

Baker, M., \& Wurgler, J. (2007). Investor sentiment in the stock market. The Journal of Economic Perspectives, 21, 129-151. http://dx.doi.org/10.1257/jep.21.2.129

Baker, M., Wurgler, J., \& Yuan, Y. (2012). Global, Local, and contagious investor sentiment. Journal of Financial Economics, 104, 272-287. http://dx.doi.org/10.1016/j.jfineco.2011.11.002

Ben-Rephael, A., Kandel, S., \& Wohl, A. (2012). Measuring investor sentiment with mutual fund flows. Journal of Financial Economics, 104, 363-382. http://dx.doi.org/10.1016/j.jineco.2010.08.018

Grundy, B. D., \& Li, H. (2010). Investor sentiment, executive compensation, and corporate investment. Journal of Banking \& Finance, 34, 2439-2449. http://dx.doi.org/10.1016/j.jbankfin.2010.03.020

Haubrich, J., George, P., \& Peter, R. (2012). Inflation Expectations, Real Rates, and Risk Premia: Evidence from Inflation Swaps. The Review of Financial Studies, 25(5), 1588-1629. http://dx.doi.org/10.1093/rfs/hhs003

Hrnjić, E., \& Sankaraguruswamy, S. (2011). Market-wide sentiment, firm-level sentiment, and IPO pricing process. Retrieved July 13, 2013, from https://fisher.osu.edu/blogs/efa2011

Kumar, A., \& Lee, C. M. C. (2006). Retail investor sentiment and return comovements. Journal of Finance, 61, 2451-2486. http://dx.doi.org/10.1111/j.1540-6261.2006.01063.x

Laborda, R., \& Olmo, J. (2013). Investor sentiment and bond risk premia. Journal of Financial Markets, http://dx.doi.org/10.1016/j.finmar.2013.05.008

MacKinnon, J. G. (1996). Numerical distribution functions for unit root and cointegration tests. Journal of Applied Econometrics, 11(6), 601-618. http://dx.doi.org/10.1002/(SICI)1099-1255(199611)11:6<601::AID-JAE417>3.0.CO;2-T

MacKinnon, J., Alfred, G., Haug, A., \& Leo, M. (1999). Numerical distribution functions of likelihood ratio tests for cointegration. Journal of Applied Econometrics, 14(5), 563-577. 
http://dx.doi.org/10.1002/(SICI)1099-1255(199909/10)14:5<563::AID-JAE530>3.0.CO;2-R

Maltritz, D., \& Alexander, M. (2013). Analyzing determinants of bond yield spreads with Bayesian Model Averaging. Journal of Banking \& Finance, 37(12), 5275-5285. http://dx.doi.org/10.1016/j.jbankfin.2013.07.007

Ng, K. Y., \& Bruce, D. P. (2011). Capturing credit spread premium. Financial Analysts Journal, 67(3), 63. http://dx.doi.org/10.2469/faj.v67.n3.4

Palomino, F., Renneboog, L., \& Zhang, C. (2009). Information salience, investor sentiment, and stock returns: The case of British soccer betting. Journal of Corporate Finance, 25, 368-387. http://dx.doi.org/10.1016/j.jcorpfin.2008.12.001

Stambaugh, R. F., Yu, J., \& Yuan, Y. (2012). The short of it: Investor sentiment and anomalies. Journal of Financial Economics, 104, 288-302. http://dx.doi.org/10.1016/j.jfineco.2011.12.001

\section{Copyrights}

Copyright for this article is retained by the author(s), with first publication rights granted to the journal.

This is an open-access article distributed under the terms and conditions of the Creative Commons Attribution license (http://creativecommons.org/licenses/by/3.0/). 